\title{
Summary Report \\ First Research Coordination Meeting on \\ Reference Database for Neutron Activation Analysis
}

\author{
IAEA Headquarters \\ Vienna, Austria
}

3-5 October 2005

\author{
Prepared by \\ Richard B. Firestone \\ Lawrence Berkeley National Laboratory \\ University of California \\ Berkeley, USA \\ and \\ Andrej Trkov \\ IAEA Nuclear Data Section \\ Vienna, Austria
}

October 2005

IAEA NUCLEAR DATA SECTION, WAGRAMER STRASSE 5, A-1400 VIENNA 
Selected INDC documents may be downloaded in electronic form from http://wwwnds.iaea.org/indc sel.html or sent as an e-mail attachment. Requests for hardcopy or e-mail transmittal should be directed to services@iaeand.iaea.org or to:

Nuclear Data Section

International Atomic Energy Agency

PO Box 100

Wagramer Strasse 5

A-1400 Vienna

Austria

Produced by the IAEA in Austria

October 2005 


\title{
Summary Report
}

\section{First Research Coordination Meeting on}

\section{Reference Database for Neutron Activation Analysis}

\author{
IAEA Headquarters \\ Vienna, Austria \\ 3-5 October 2005 \\ Prepared by \\ Richard B. Firestone \\ Lawrence Berkeley National Laboratory \\ University of California \\ Berkeley, USA \\ and \\ Andrej Trkov \\ IAEA Nuclear Data Section \\ Vienna, Austria
}

\begin{abstract}
Potential problems associated with nuclear data for neutron activation analysis were identified, the scope of the work to be undertaken was defined together with its priorities, and tasks were assigned to participants. Data testing and measurements refer to gamma spectrum peak evaluations, detector efficiency calibration, neutron spectrum characteristics and reference materials analysis.
\end{abstract}



TABLE OF CONTENTS

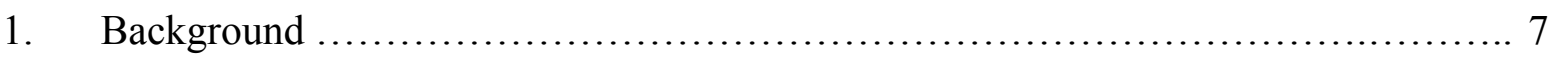

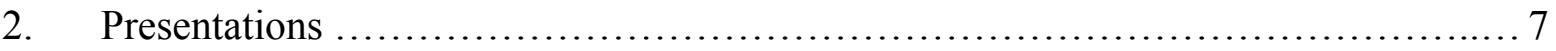

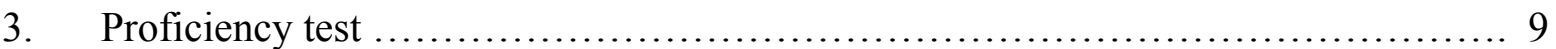

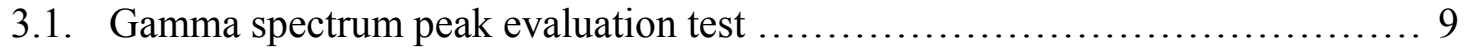

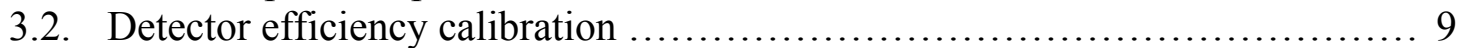

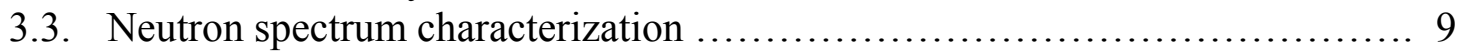

3.4. Materials analysis test ............................................. 10

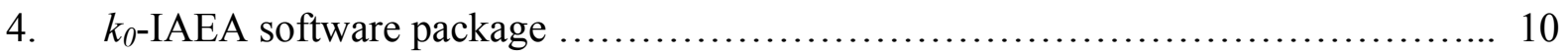

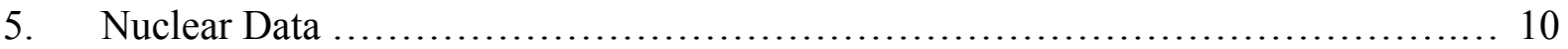

6. Criteria for determining priorities and scope of new measurements ................ 10

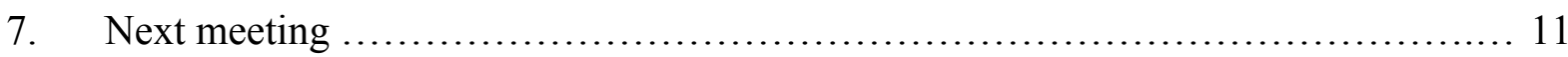

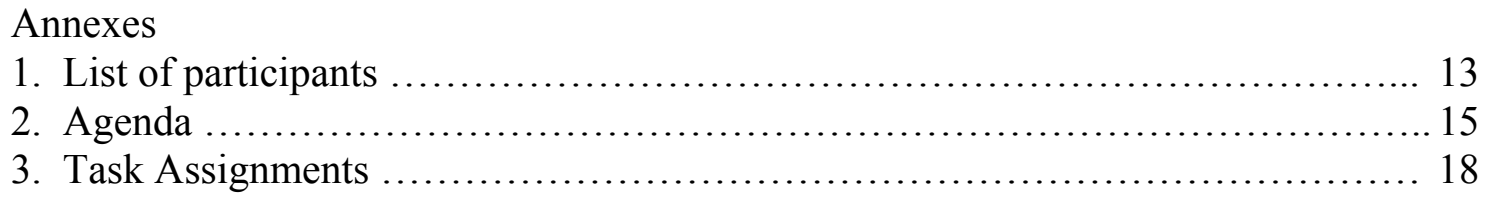





\section{Background}

Due to its selectivity and sensitivity, neutron activation analysis (NAA) occupies an important place among the various analytical methods. It has proven to be a powerful non-destructive analytical technique for concentrations at or below the $\mu \mathrm{g} / \mathrm{g}$ range, while up to 60 elements can be determined performing two irradiations and several gamma-spectrum measurements after different decay periods. The main fields of NAA application are analytical chemistry, geology, biology, and the life and environmental sciences. Its accuracy, the virtual absence of matrix effects and the completely different physical basis when compared to other analytical techniques, make it particularly suitable for the certification of candidate reference materials (RMs), providing e.g. the bulk of the literature data on the standard RMs of the National Institute of Standards and Technology and reference materials of the International Atomic Energy Agency.

The $k_{0}$ standardisation method of NAA ( $k_{0}$-NAA), a concept launched in 1975, can be interpreted as an absolute standardisation method. It relies on $k_{0}$ and $Q_{0}$ factors and a few other parameters that are composite constants derived from the basic nuclear data. In practice, they are usually determined by direct measurements, partly because equivalent constants derived from the basic data are often discrepant.

The aim of the Co-ordinated Research Project (CRP) on the Reference Database for Neutron Activation Analysis is to improve the status of the database of nuclear constants for $k_{0}$-NAA, to contribute to nuclear structure and decay data and to remove or reduce some of the discrepancies that exist between the integral constants and values derived from differential data.

The INDC Committee reviews the programme of the IAEA-NDS, and has endorsed the CRP at their meeting held in May 2002. A complementary project is in progress at NAPCIndustrial Applications and Chemistry Section on " $k_{0}$-IAEA Software Development for Neutron Activation Analysis". This software package is chosen as the reference analysis tool for the current CRP.

The first Research Co-ordination Meeting (RCM) was held at the Agency Headquarters on 35 October 2005. The report below is a summary of the conclusions from that meeting.

\section{Presentations}

\section{A. Trkov, IAEA-NDS}

The objectives of the CRP were re-iterated, namely:

- $\quad$ to improve database of nuclear constants for $k_{0}$ NAA (improved $k_{0}$ library),

- to improve consistency between integral and differential data (activation cross-section library),

- $\quad$ to contribute to nuclear structure and decay data (EGAF database),

- $\quad$ to extend applicability of $k_{0}$ NAA.

Methods and procedures will be investigated for detector calibration, neutron spectrum characterization and gamma-spectrum processing methods. The nuclear database of integral constants will also be reviewed, performing new measurements as required. 


\section{F. De Corte, Ghent University, Belgium}

A historical overview and the milestones in the most significant advances of the method were presented, explaining how the database was assembled and verified. Such information is essential for planning new measurements in order to generalize and improve the database.

\section{R. Jaćimović, Institute Jožef Stefan, Ljubljana, Slovenia}

The $k_{0}$-method was introduced at the Jožef Stefan Institute (JSI) in Ljubljana at the end of 1988. Since then all recommended procedures for applying $k_{0}$-standardization method using TRIGA Mark II reactor have been implemented. The validation of the $k_{0}$ method was established via the analysis of different reference and certified reference materials issued by the IAEA, NIST, BCR and IRMM. Up to now, relevant investigations for the CRP were done as follows: accurate determination of neutron spectrum parameters $(f$ and $\alpha)$ in different irradiation channels, time-dependence of the neutron flux in different irradiation channels of the TRIGA reactor, neutron flux gradients (axial and radial) inside the irradiation channels, azimuthal variation of the neutron flux in the carousel facility (CF) of the TRIGA reactor, verification of Monte Carlo calculation of the neutron flux in CF, burn-up effects for some nuclides and systematic errors in the procedure for full-energy peak detection efficiency $\left(\varepsilon_{\mathrm{p}}\right)$ for an HPGe detector.

\section{B. Smodiš, Institute Jožef Stefan, Ljubljana, Slovenia}

Elements were identified that have incomplete information on uncertainties in their nuclear data. These should be addressed with high priority so that error propagation in routine measurements can be carried out correctly.

\section{S.A. Jonah, Ahmadu Bello University, Nigeria}

A description of the Nigerian MNSR (NIRR-1) and the experimental facilities was provided. Special mention was made of the current status of the facilities used for NAA by the relative method. In this regard, experimental procedures developed for sample analyses by the conventional method for over 30 elements were described. Measured neutron spectrum parameters required for the applicability of the $k_{0}$-standardization method were provided. The group's contribution to the CRP will be in the improvement of methodologies for determination of neutron spectrum parameters, measurement of some nuclear constants and the testing of the $k_{0}$-IAEA software.

\section{Maria Arribere, Centro Atomico Bariloche, Argentina}

The main goals of the group within this CRP are:

i) perform core modeling by using Monte Carlo techniques,

ii) perform flux characterization in the RA-6 irradiation positions through activity measurements and computational deterministic and statistical modelling,

iii) use characterized irradiation channels to perform measurements of nuclear parameters of interest in NAA using the $k_{0}$ method,

iv) use characterized irradiation channels to measure resonance integrals and thermal cross sections of isotopes where both the ground and metastable states are formed, using the methodology developed at the laboratory that has already been applied to threshold reactions. 


\section{Richard Firestone, Lawrence Berkeley National Laboratory, Berkeley CA, USA}

Neutron activation analysis $k_{0}$ data will be compared with gamma-ray transition probabilities from the ENSDF and DDEP decay data files and with data from the EGAF $k_{0}$ file. New adopted decay, $k_{0}$ and cross-section data will be added into EGAF.

\section{Zsolt Revay, KFKI, Budapest}

In-beam activation technique is an excellent tool for measuring $k_{0}$ factors using pure thermal neutrons, and also for studying isotopes with short half-lives. The calculation of self-shielding is also simple in beam geometry. Moreover, when the activation is performed in a cold neutron beam, the effects of resonances disappear. A series of measurements have been started at the Prompt Gamma Activation Analysis facility of the Budapest Research Reactor to re-determine $k_{0}$ factors in the cold neutron beam. For a series of elements (like $\mathrm{Na}, \mathrm{Al}, \mathrm{F}$, $\mathrm{Mn}$ ), the decay peaks proved to be strong enough to analyze them in the usual prompt-gamma spectra. For weaker peaks the chopped-beam techniques is appropriate to separate the decay peaks from the prompt gamma spectrum. The elements from the priority list will be measured with either technique. The neutron spectrum was determined at the PGAA facility with timeof-flight technique using the beam chopper, and this will be done every time the beam configuration is changed. This information is used in the determination of effective $g$ factors for nuclides such as ${ }^{147} \mathrm{Gd},{ }^{113} \mathrm{Cd}$, etc. This project is already going on.

\section{Proficiency test}

The purpose of the proficiency test is to ensure that irradiation facilities and analysis software of the participants contributing experimental data will produce consistent results.

Proficiency tests will involve detector calibration, peak area determinations and neutron spectrum characterizations. Analysis will be done with $k_{0}$-IAEA software and other methods that may be available to the participants.

\subsection{Gamma spectrum peak evaluation test}

The coordinator for the peak evaluation test will be Menno Blaauw. He will provide standard spectra for the purpose. Participants will submit results to the coordinator who will summarize the contributions at the next meeting.

\subsection{Detector efficiency calibration}

The coordinator for the efficiency calibration will be Zsolt Revay. He will provide standard calibration spectra and calibration data. Participants will submit the specified results to the coordinator who will summarize the contributions at the next meeting.

\subsection{Neutron spectrum characterization}

The coordinator for neutron spectrum characterization will be Andrej Trkov. Monitoring material from the $k_{0}$-IAEA package will be used by all participants for spectrum characterization of their irradiation facility. In addition, Frans De Corte will provide recommendations for other candidate materials that have suitable capture and threshold reactions.

The participants will be expected to determine $f$ and $\alpha$ by conventional methods. If available, participants will also provide neutron spectra in 640 group structure from statistical model 
calculations or from direct measurements. Spectrum characterization results will be sent to Andrej Trkov for further analysis.

\subsection{Materials analysis test}

All participants will perform a materials analysis test. Frans De Corte will review the availability and appropriateness of using synthetic multi-element standard materials (SMELS) or a suitable substitute. He will also look into the future possibility of SMELS production. Maria Arribere will collect the results of the materials analysis test and write a report for the next RCM meeting.

\section{4. $k_{0}$-IAEA software package}

Recently introduced features of the $k_{0}$-IAEA software were discussed. Menno Blaauw will distribute the latest update of $k_{0}$-IAEA software to all participants.

\section{Nuclear Data}

Definitions of nuclear constants and their relation to differential data will also be provided by Andrej Trkov, who will also calculate a) self-shielding factors as a function of the Bondarenko dilution cross section, b) effective resonance energies and c) effective $g$-factors from the same data source.

If changes in the $k_{0}$ database are needed, all constants for a nuclide will be reviewed.

Data currently in the $k_{0}$ database will be compared with equivalent data from other sources. The purpose of this intercomparison exercises is to identify discrepant data that may require re-evaluation or new measurements.

$P_{\gamma}$ and $k_{0}$ values will be compared and evaluated for the EGAF library by Richard Firestone. Data from the $k_{0}$ database, ENSDF, DDEP, EGAF and the literature will be considered.

Half-life data from the $k_{0}$ database provided by Frans De Corte will be compared by Mark Kellett with values from the evaluated databases.

Andrej Trkov will compare $Q_{0}$ values from the $k_{0}$ database with IRDF-2002 and JEFF-3.1 activation library.

\section{Criteria for determining priorities and scope of new measurements}

Priorities for re-evaluation or re-measurement of constants for the $k_{0}$ database have been elaborated as follows.

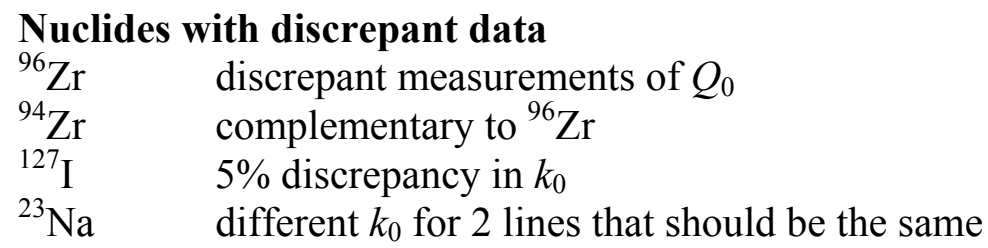


${ }^{27} \mathrm{Al} \quad 2 \sigma$ discrepancy between recommended and $k_{0}$ measured at KFKI

${ }^{131} \mathrm{Ba} \quad$ inconsistent measurements for $k_{0}$ and $Q_{0}$

${ }^{138} \mathrm{Ba}$ inconsistent measurements for $k_{0}$ and $Q_{0}$

${ }^{121} \mathrm{Sb}$ discrepancy in $k_{0}, Q_{0}$ resulting in different concentrations from 2 isotopes

${ }^{123} \mathrm{Sb}$ discrepancy in $k_{0}, Q_{0}$ resulting in different concentrations from 2 isotopes

Important monitor materials

${ }^{64} \mathrm{Zn}$

${ }^{68} \mathrm{Zn}$

\section{Non-1/v absorbers}

List will be provided by Zsolt Revay.

Nuclides with high effective resonance energy $E_{\mathbf{r}}$

$Q_{0} \quad E_{\mathrm{r}} \quad$ Isotope $\quad \sigma_{0}$

$5.934300{ }^{90 \mathrm{~m}_{\mathrm{Y}}} \quad 0.001$

$5.056260{ }^{95} \mathrm{Zr} \quad 0.0499$

Lower priority $\left(Q_{0}<5\right)$

\begin{tabular}{|c|c|c|}
\hline & & \\
\hline 1.12 & $2280{ }^{37} \mathrm{~S}$ & 0.1 \\
\hline 1.14 & $1040{ }^{64} \mathrm{Cu}$ & $2.1^{\prime}$ \\
\hline 1.908 & $32560{ }^{65} \mathrm{Zn}$ & 0.7 \\
\hline 2.38 & $3540{ }^{75 \mathrm{~m}} \mathrm{Ge} 0.17$ & \\
\hline 1.57 & $3540{ }^{75} \mathrm{Ge}$ & 0.3 \\
\hline 1.8 & $2950{ }^{131} \mathrm{I}$ & 6.2 \\
\hline 1.2 & $1540{ }^{143} \mathrm{Ce}$ & 0.9 \\
\hline
\end{tabular}

Additional candidate materials for review will be identified by the intercomparison exercise described in Section 5. Also, Zsolt Revay will consult with Greg Kennedy whether any additional materials need to be included in the list.

There was general consensus that voluntary contributions from qualified researchers or laboratories will be valued for analysis and inclusion in the final database as appropriate. The authors will be acknowledged in the final document.

The web page is maintained by NDS for efficient exchange of information between interested parties, but is not advertised from the main web page. None of the participants objected to making the address known to potential contributors who are not formally CRP participants.

\section{Next meeting}

The next RCM meeting is scheduled in Spring 2007, the venue and the date to be decided. 
$-12-$ 
International Atomic Energy Agency

First Research Co-ordination Meeting on

"Reference Database for Neutron Activation Analysis"

IAEA Headquarters, Vienna, Austria

3-5 October 2005

Meeting Room ACV-03-250

\section{LIST OF PARTICIPANTS}

\section{ARGENTINA}

Maria A. Arribere

Centro Atomico Bariloche

Comision Nacional de Energia Atomica

Bustillo 9500

8400 Bariloche

Rio Negro

Tel: $\quad+54$ (2944) 445240

Fax: +54 (2944) 445299

E-mail: arribere@cab.cnea.gov.ar

\section{BELGIUM}

Frans De Corte

Ghent University

INW-Proeftuinstraat 86

B-9000 Gent

Tel: $\quad+3292646627$

Fax: +32 92646699

E-mail: frans.decorte@,Ugent.be

\section{HUNGARY}

Zsolt Revay

Institute of Isotopes

Chemical Research Centre

Hungarian Academy of Sciences

Department of Nuclear Research

H-1121 Budapest, Konkoly Thege Str. 29-33

Tel: $\quad+3613922539$

Fax: +361392 2584

E-mail: revay@iki.kfki.hu

\section{NIGERIA}

Sunday A. Jonah

Centre for Energy Research and Training

(CERT)

Ahmadu Bello University

PMB 1014 Zaria

Tel: $\quad+23469550397$

Fax: +23469550737

E-mail: jonahsa2001@yahoo.com

\section{SLOVENIA}

Radojko Jaćimović

Laboratory for Radiochemistry

Department of Environmental Sciences

Institute Jožef Stefan

Jamova 39

Sl-1000 Ljubljana

Tel: +38615885353

Fax: +38615885346

E-mail: radojko.jacimovic@ijs.si

\section{UNITED STATES OF AMERICA}

Richard B. Firestone

Lawrence Berkeley National Laboratory

University of California

1 Cyclotron Road, M/S 88RO192

Berkeley, CA 94720-8101

Tel: $\quad+15104867646$

Fax: +1 5104865757

E-mail: RBF@lbl.gov

\section{ADVISOR}

\section{THE NETHERLANDS}

Menno Blaauw

Reactor Institute Delft

Facilities \& Services Dept.

Mekelweg 15

NL-2629 JB Delft

Tel: $\quad+31152783538$

Fax: +31 152788430

E-mail:m.blaauw@tnw.tudelft.nl

\section{OBSERVER}

SLOVENIA

Borut Smodiš

Institute Jožef Stefan

Jamova 39

Sl-1000 Ljubljana

Tel: +38612885450

E-mail: Borut.Smodis@ijs.si 


\section{IAEA:}

Andrej Trkov

Nuclear Data Section

Division of Physical and Chemical Sciences

Room A2316

Tel: $\quad+4312600-21712$

Fax: +43126007

E-mail: A.Trkov@iaea.org

Alan L. Nichols

Nuclear Data Section

Division of Physical and Chemical Sciences

Room A2313

Tel: $\quad+4312600-21709$

Fax: +43 126007

E-mail: A.Nichols@iaea.org

Mark A. Kellett

Nuclear Data Section

Division of Physical and Chemical Sciences

Room A2319

Tel: $\quad+431260021708$

Fax: +4312600721708

E-mail: M.A.Kellett@iaea.org

Matthias Rossbach

Industrial Applications and Chemistry Section Division of Physical and Chemical Sciences

Room A2370

Tel: $\quad+431260021750$

Fax: +4312600721750

E-mail: M.Rossbach@iaea.org

Chushiro Yonezawa

Nutritional and Health Related Environmental

Studies Section

Division of Human Health

Room A2424

Tel: $\quad+431260021652$

Fax: +4312600721652

E-mail: C.Yonezawa@iaea.org 
International Atomic Energy Agency

First Research Coordination Meeting on

Reference Database for Neutron Activation Analysis

IAEA Headquarters, Vienna, Austria

3 - 5 October 2005

Meeting Room ACV-03-250

\section{AGENDA}

\section{Monday, 3 October}

08:30 - 09:20 Registration (IAEA registration desk, Gate 1)

09:30 - 10:00 Opening Session

Opening by Mr. N. Ramamoorthy, Director-NAPC

Introductory remarks (A.Trkov)

Election of Chairman and Rapporteur

Discussion and adoption of the Agenda (Chairman)

Election of task co-ordinators

10:00 - 11:00 Coffee break and Administrative Matters

11:00 - 12:20 Session 1: Presentations by participants

(max: 15 min per presentation +5 min discussion)

12:20 - 14:00 Lunch

14:00 - 15:30 Session 2: Presentations by participants (cont'd.)

(max: 15 min per presentation +5 min discussion)

General Discussion

15:30 - 16:00 Coffee break

16:00 - 17:30 Session 3: Definition of a proficiency test case

Detector calibration

Neutron spectrum determination / monitor reactions

Gamma spectrum analysis

Processing of results

General Discussion

17:30 onwards Social event 
Tuesday, 4 October

08:30 - 09:30 Session 4: Neutron spectrum determination

Conventional methods of NAA

Spectrum unfolding

Direct measurements

Computational methods

General Discussion

09:30 - 10:15 Session 5: $\boldsymbol{k}_{0}$-IAEA software package

Detector calibration utilities

Spectrum processing utilities

Scope of software intercomparison with other products

Software extensions

General Discussion

10:15 - 10:45 Coffee break

10:45 - 12:15 Session 6: Specific features

Items drafted by chairman

12:15 - 14:00 Lunch

14:00 - 15:30 Session 7: Nuclear constants in relation to differential data

Relation between integral and differential data

Neutron self-shielding

Effective resonance energy

Gamma emission probabilities

15:30 - 16:00 Coffee break

16:00 - 17:30 Session 8: Criteria for determining the scope of new measurements

Needs and priorities

Available facilities

Available manpower

\section{Wednesday, 5 October}

08:30 - 10:15 Session 9: Task assignment and drafting of summary report

10:15 - 10:45 Coffee break

10:45 - 12:15 Session 10: Task assignment and drafting of summary report

12:15 - 14:00 Lunch

14:00 - 15:30 Session 11: Review of the summary report

15:30

Closing of the meeting 


\section{GUIDELINES}

\section{General:}

- Please, check the NAA CRP web page http://www-nds.iaea.org/naa/index.html frequently for announcements and up-to-date information.

- For all administrative queries please contact Ms. Janet Roberts on J.Roberts@,iaea.org.

- For technical matters please contact the technical officer of the project Andrej Trkov on A.Trkov@iaea.org. with a copy to Ms. Roberts.

\section{Presentations:}

- Oral presentations at the meeting are deliberately short.

- The presentations should not describe details of the theoretical advances, but primarily inform other participants (not necessarily experts in the specific field) on your planned contribution to the CRP. 
TASK ASSIGNMENTS

\begin{tabular}{|c|c|c|c|}
\hline Participant & Date & Task & Status \\
\hline \multirow{3}{*}{ Menno Blaauw } & & Gamma spectrum peak evaluation test. & \\
\hline & 11 July 2006 & Coordinate activity. & \\
\hline & 5 Dec. 2005 & $\begin{array}{l}\text { Provide standard spectra for purpose to } \\
\text { participants. }\end{array}$ & \\
\hline All participants & 30 April 2006 & Submit results to coordinator. & \\
\hline \multirow[t]{2}{*}{ Menno Blaauw } & Next RCM & Summarize contributions. & \\
\hline & & Detector efficiency calibration. & \\
\hline Zsolt Revay & May 2006 & $\begin{array}{l}\text { Coordinate activity. } \\
\text { Provide standard calibration spectra and } \\
\text { calibration data to participants. }\end{array}$ & \\
\hline All participants & 31 Oct 2006 & $\begin{array}{l}\text { Submit results according to specifications to } \\
\text { coordinator. }\end{array}$ & \\
\hline \multirow[t]{2}{*}{ Zsolt Revay } & Next RCM & Summarize contributions. & \\
\hline & & Neutron spectrum characterization. & \\
\hline Andrej Trkov & Next RCM & Coordinate activity. & \\
\hline Frans De Corte & Dec. 2005 & $\begin{array}{l}\text { Provide recommendations for other candidate } \\
\text { materials that have suitable capture and } \\
\text { threshold reactions. }\end{array}$ & Done \\
\hline All participants & Dec. 2006 & $\begin{array}{l}\text { Monitoring material from the } k_{0} \text {-IAEA package } \\
\text { to be used by all participants for spectrum } \\
\text { characterization of their irradiation facility, in } \\
\text { addition to any other available monitor } \\
\text { materials. Determine } f \text { and } \alpha \text { by conventional } \\
\text { methods. }\end{array}$ & \\
\hline All participants & Dec. 2006 & $\begin{array}{l}\text { If available, also provide neutron spectra in } 640 \\
\text { group structure from statistical model } \\
\text { calculations or from direct measurements. } \\
\text { To be sent to Andrej Trkov for further analysis. }\end{array}$ & \\
\hline Andrej Trkov & Next RCM & $\begin{array}{l}\text { Further analysis of spectrum characterization } \\
\text { results. }\end{array}$ & \\
\hline \multirow[t]{2}{*}{ Andrej Trkov } & Next RCM & Summarize contributions. & \\
\hline & & Materials analysis test. & \\
\hline Maria Arribere & Next RCM & Coordinate activity. & \\
\hline All participants & Next RCM & To perform a materials analysis test. & \\
\hline
\end{tabular}




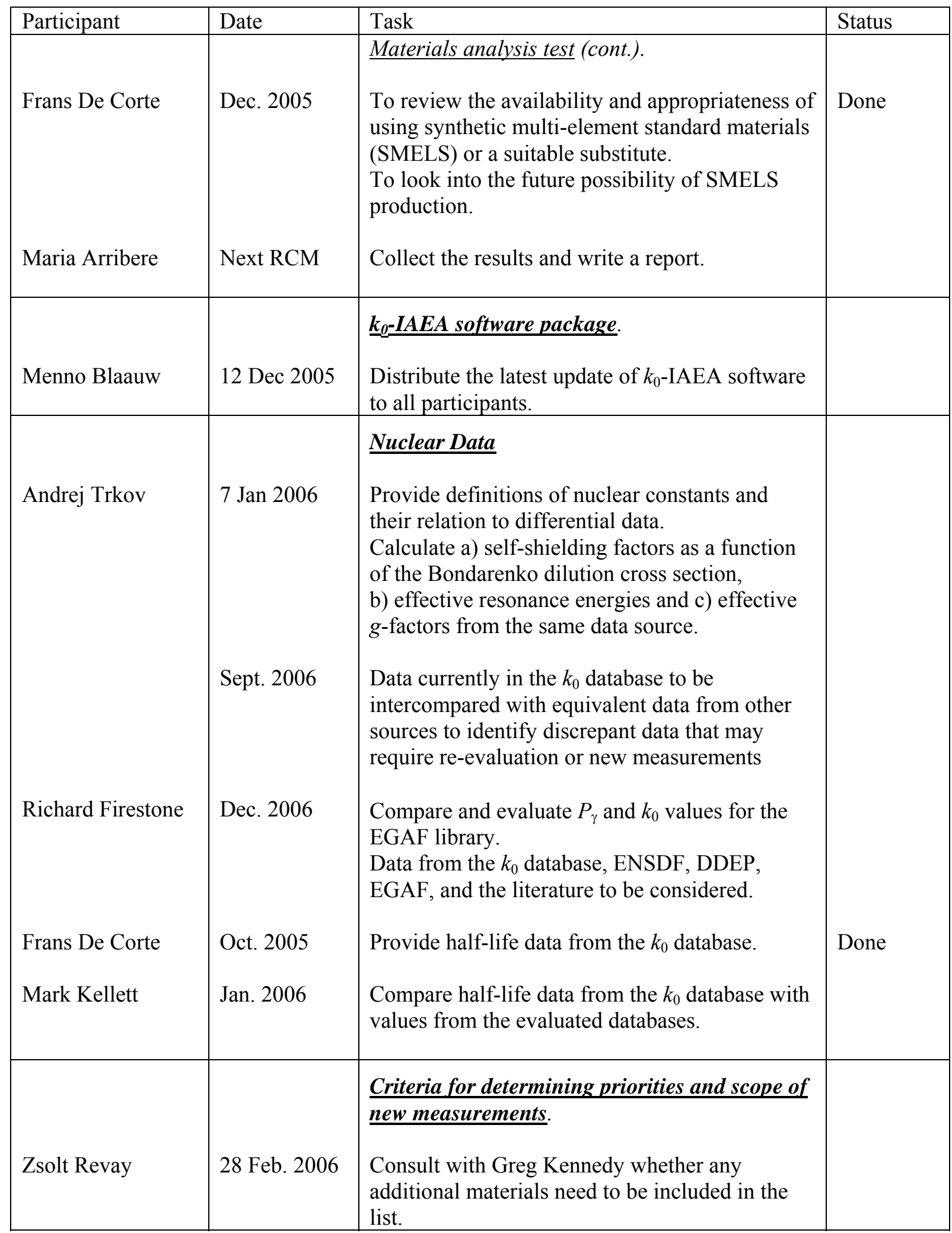




Nuclear Data Section

International Atomic Energy Agency

P.O. Box 100

A-1400 Vienna

Austria e-mail: services@iaeand.iaea.org

fax: (43-1) 26007

cable: INATOM VIENNA

telex: $1-12645$

telephone: (43-1) 2600-21710 